\title{
The onset of nausea and vomiting of pregnancy: a prospective cohort study
}

\author{
Roger Gadsby², Diana Ivanova' ${ }^{1}$ Emma Trevelyan ${ }^{1}$, Jane L. Hutton ${ }^{{ }^{*}}$ (D) and Sarah Johnson ${ }^{3}$
}

\begin{abstract}
Background: Nausea and vomiting are experienced by most women during pregnancy. The onset is usually related to Last Menstrual Period (LMP) the date of which is often unreliable. This study describes the time to onset of nausea and vomiting symptoms from date of ovulation and compares this to date of last menstrual period

Methods: Prospective cohort of women seeking to become pregnant, recruited from 12 May 2014 to 25 November 2016, in the United Kingdom. Daily diaries of nausea and vomiting were kept by 256 women who were trying to conceive. The main outcome measure is the number of days from last menstrual period (LMP) or luteinising hormone surge until onset of nausea or vomiting.

Results: Almost all women (88\%) had Human Chorionic Gonadotrophin rise within 8 to 10 days of ovulation; the equivalent interval from LMP was 20 to 30 days. Many (67\%) women experience symptoms within 11 to 20 days of ovulation.
\end{abstract}

Conclusions: Onset of nausea and vomiting occurs earlier than previously reported and there is a narrow window for onset of symptoms. This indicates that its etiology is associated with a specific developmental stage at the foetal-maternal interface.

Trial registration: NCT01577147. Date of registration 13 April 2012

Keywords: Pregnancy, Nausea, Vomiting, Onset, Last menstrual period, Luteinising hormone (LH) surge

\section{Background}

Nausea and vomiting of pregnancy (NVP) has been recognised as a feature of early pregnancy for well over 2000 years. Hippocrates who lived from 460 to $370 \mathrm{BC}$ wrote "when a woman who is suffering from neither rigours nor fever, develops amenorrhea and is liable to nausea, she is pregnant" [1]. Different national guidelines recommend different approaches to the management of NVP, with a wide range of recommendations [2].

The precise date and the characteristics of its onset have been more difficult to define. Several papers that describe onset $[3,4]$ have collected data retrospectively by asking women to describe their onset when they attend their

*Correspondence: J.L.Hutton@warwick.ac.uk

${ }^{3}$ SPD Development Company Limited, Stannard Way, MK44 3UP Bedford, UK Full list of author information is available at the end of the article first ante-natal clinic often at around 12 weeks from last menstrual period (LMP). Such retrospective data may be particularly unreliable if symptoms are mild and have subsided by the time of data collection. In the Canadian study, $74 \%$ of women reported nausea [4]. A study describing the onset and natural history of NVP that asked women to present when they first thought they were pregnant so as to enter the study as early as possible in order to collect symptoms prospectively, reported entry at a median of day 57 from LMP. In that study 58 (16\%) of women out of a study population of 363 reported symptoms before entry, some of them up to 14 days before entry [5]. Using LMP to date onset of pregnancy nausea and vomiting may also be problematic. Some studies have shown that only $32 \%$ of women were certain of the date of their LMP [6]. A higher incidence of round number preferences were recorded when women were asked the date of their LMP 
with the 15th of the month given 2.5 times more often than expected [7].

A much more accurate way of dating a pregnancy is from using the date of ovulation which can be determined by measuring the surge in luteinising hormone (LH) that stimulates ovulation [8]. The cause of NVP is still largely unknown, but is thought to be multifactorial, with a genetic element in its aetiology [9]. A psychiatric aetiology has been proposed in the past but, although this has been disproven [10], sufferers feel that this remains an inhibitor to the empathy and care the condition deserves [10]. Women who have experienced severe NVP are very keen to stress the biological nature of the condition [11]. Evidence that there is a very close association between the onset of NVP symptoms and the onset of pregnancy, as measured from the date of ovulation, would provide further evidence for a biological aetiology.

In this paper we study the onset of NVP in relation to the date of ovulation and LMP

\section{Methods}

A cohort study conducted by SPD Development Company Limited (SPD) was originally designed to investigate hormone levels in early pregnancy. It was extended to include the study of pregnancy sickness and vomiting; the methodology has described previously [12]. In brief, the study was registered (NCT01577147) and ran from 15 May 2014 to 17 February 2017. Volunteers were recruited preconception, and all gave written consent for the homebased study. Inclusion criteria were: at least 18 years old and seeking to become pregnant and has regular menstrual periods. Exclusion criteria were: medical conditions that contra-indicate pregnancy, known infertility or having treatment for infertility or women who were currently pregnant.

Volunteer demographics, menstrual cycle information and previous pregnancy history were collected at admission. From day 1 of their next menstrual cycle, volunteers collected a daily early morning urine sample and completed a daily diary. Lutenising hormone (LH) was measured (AutoDELFIA, Perkin Elmer) in order to determine the day of LH surge, which precedes ovulation by approximately 1 day. Human Chorionic Gonadotrophin (hCG) was measured (AutoDELFIA, Perkin Elmer) in late luteal phase and throughout early pregnancy, in order to identify viable pregnancy and early pregnancy loss.

Home pregnancy tests were provided to volunteers. When a volunteer reported pregnancy to the study site, she was instructed to record each hour of nausea and vomiting symptoms in a diary. The questionnaire was adapted from the PUQE score system for recording nausea and vomiting to allow more details of times (Supplementary material 1: Diary). The instructions were to start recording on day 30 following LMP (date of last menstrual period), and stop at day 60 from LMP. Hence participants started the diaries on different days of their pregnancy. Woman who did not achieve pregnancy were instructed to collect urine samples and complete symptom diaries only up to day 7 of her next cycle.

\section{Statistical methods}

The anonymised dataset was transferred to the Department of Statistics at the University of Warwick and examined by Master's students using R Studio statistical Software. Standard summary statistics, linear regression and significance tests were used. For the table, age and hours per day of symptoms were split approximately into thirds, and body mass index (BMI, $\mathrm{kg} / \mathrm{m}^{2}$ ) into normal, overweight and obese categories. For investigation of time to onset of symptoms by age and BMI, the variables were continuous. A NVP score was calculated as the average daily hours of nausea and vomiting based on the time period the women reported, using available data. A high level summary of symptom severity is given; results for diurnal variation are given elsewhere [12].

\section{Results}

\section{Study population}

Initially, 1443 women who were planning to become pregnant were recruited into the study. 1073 of those women did not achieve pregnancy in a one-month period, 17 women had a miscarriage and 65 women had early losses. Out of the remaining 288, who successfully conceived, 32 dropped out of the study. Hence, the study population includes 256 women. Only 866 samples of the expected 16830 urine samples were missing from the daily sample collections, providing $95 \%$ coverage.

Many, $60 \%$, of the women had previously had live births, mainly one child (Table 1 , Total column). The mean age was 30.4 years, the mean age of mothers in England and Wales in 2016 [13]; age ranged from 18 to 43 . The majority $(54 \%)$ of younger women $(<28)$ in the study had no children, and half of women over 32 had one child. Most (95\%) of the women were white and were European. The mean BMI was $27.0 \mathrm{~kg} / \mathrm{m}^{2}$, standard deviation $6.1 \mathrm{~kg} / \mathrm{m}^{2}$. Half $(53 \%)$ the women were overweight or obese, and $9 \%$ were underweight; one BMI was missing. Almost half (43\%) of the population had previously suffered at least one miscarriage, with more miscarriages associated with more live births. Most participants (75\%) had an education level of A-levels or higher, and more of these women (43\%) had no previous live births, although those with degrees were older than those without Alevels. Before conceiving during this study, volunteers had been trying for a mean of 8.42 months, median of 5 months.

\section{Daily diaries}

Only 10 women had any missing daily symptom diaries; 
Table 1 Characteristics of 256 women in nausea and vomiting diary study

\begin{tabular}{|c|c|c|c|c|}
\hline \multirow[t]{2}{*}{ Characteristic } & \multicolumn{3}{|c|}{ Average hours per day Nausea and Vomiting } & \multirow[t]{2}{*}{ Totals } \\
\hline & $<1,5$ hours/day & $(1.5,4]$ hours/day & $\geq 4$ hours/day & \\
\hline All women & $56(22 \%)$ & $108(42 \%)$ & $92(36 \%)$ & $256(100 \%)$ \\
\hline \multicolumn{5}{|l|}{ Age } \\
\hline $18-28$ & $20(24 \%)$ & $40(48 \%)$ & $24(29 \%)$ & $84(33 \%)$ \\
\hline $29-32$ & $22(23 \%)$ & $44(45 \%)$ & $31(32 \%)$ & $97(38 \%)$ \\
\hline $33-43$ & $14(19 \%)$ & $24(32 \%)$ & $37(49 \%)$ & $75(29 \%)$ \\
\hline \multicolumn{5}{|l|}{ BMI } \\
\hline$\leq 25 \mathrm{~kg} / \mathrm{m}^{2}$ & $32(27 \%)$ & $53(45 \%)$ & $34(29 \%)$ & $119(46 \%)$ \\
\hline$(25,30] \mathrm{kg} / \mathrm{m}^{2}$ & $18(24 \%)$ & $30(32 \%)$ & $28(44 \%)$ & $63(25 \%)$ \\
\hline$>30 \mathrm{~kg} / \mathrm{m}^{2}$ & $8(11 \%)$ & $34(47 \%)$ & $30(42 \%)$ & $72(28 \%)$ \\
\hline \multicolumn{5}{|l|}{ Smoking } \\
\hline Current or ex & $37(24 \%)$ & $54(35 \%)$ & $42(42 \%)$ & $100(39 \%)$ \\
\hline Never & $19(19 \%)$ & $54(54 \%)$ & $27(47 \%)$ & $156(61 \%)$ \\
\hline \multicolumn{5}{|c|}{ Previous live births } \\
\hline 0 & $28(27 \%)$ & $52(50 \%)$ & $23(22 \%)$ & $100(40 \%)$ \\
\hline 1 & $21(20 \%)$ & $39(37 \%)$ & $45(43 \%)$ & $105(41 \%)$ \\
\hline$\geq 2$ & $7(15 \%)$ & $17(35 \%)$ & $24(50 \%)$ & $48(19 \%)$ \\
\hline \multicolumn{5}{|l|}{ Miscarriages } \\
\hline 0 & $35(24 \%)$ & $60(41 \%)$ & $50(34 \%)$ & $145(57 \%)$ \\
\hline 1 & $12(18 \%)$ & 35 (51\%) & $21(31 \%)$ & $68(27 \%)$ \\
\hline$\geq 2$ & $9(21 \%)$ & $13(30 \%)$ & $21(49 \%)$ & $43(17 \%)$ \\
\hline \multicolumn{5}{|l|}{ Education level } \\
\hline Below A-level & $11(17 \%)$ & 35 (56\%) & $17(27 \%)$ & $63(25 \%)$ \\
\hline A-levels & $16(19 \%)$ & $32(38 \%)$ & $36(43 \%)$ & $84(33 \%)$ \\
\hline Degree level & $29(27 \%)$ & $41(38 \%)$ & $39(36 \%)$ & 109 (43\%) \\
\hline
\end{tabular}

9 missed a single day and one missed three days. As this is negligible, the overall NVP scores for each women used available data. $61 \%(\mathrm{n}=148)$ of the volunteers with NVP started filling in their daily diaries before they had their first symptoms. The remaining 93 participants first filled in their daily diaries on the first day they experienced symptoms. Their mean onset was a week earlier than those who started diaries before first symptoms, so there is no reason to believe symptoms occured before the first recorded day.

Most women, $94.1 \%(n=241)$ had some symptoms of NVP. In particular, $35 \%(\mathrm{n}=89)$ of the women experienced just nausea, $59 \%(n=150)$ suffered from both nausea and vomiting. Two volunteers reported to have had only vomiting, however the intensity was respectively 1 hour and 4 hours of sickness (vomiting) throughout their whole pregnancies. Women with more than one previous live births experience significantly longer average hours of symptoms per day, median 3.9 hours.

\section{LMP vs. ovulation}

By convention and in all relevant to NVP literature, LMP is considered as the beginning of pregnancy. Nevertheless, this is somewhat inaccurate as for women with monthly cycles of different lengths, the time between LMP and ovulation and hence between LMP and fertility or impregnation varies. Nevertheless, as the ovulation day can be calculated by the LH surge, it was included in this data set. The inclusion of both of these dates in the data set allows for a comparison of their accuracy as a measure of the start of pregnancy. As the concentration of hCG is an ideal marker of pregnancy [8], comparing the dates of LMP and ovulation to the first date when the pregnancy hormone hCG first reached a concentration of 1 $\mathrm{mIU} / \mathrm{ml}$ (the hCG rise) can be expected to give an accurate result of the comparison. Figure 1 compares the duration to start of pregnancy. Almost all women (88\%) had hCG rise within 8 to 10 days of ovulation. Only $3 \%$ had intervals less than 8 days, and $9 \%$ more than 10 days. The time 


\section{Days from LMP and ovulation to $\mathrm{hCG}>1 \mathrm{mlU} / \mathrm{ml}$}

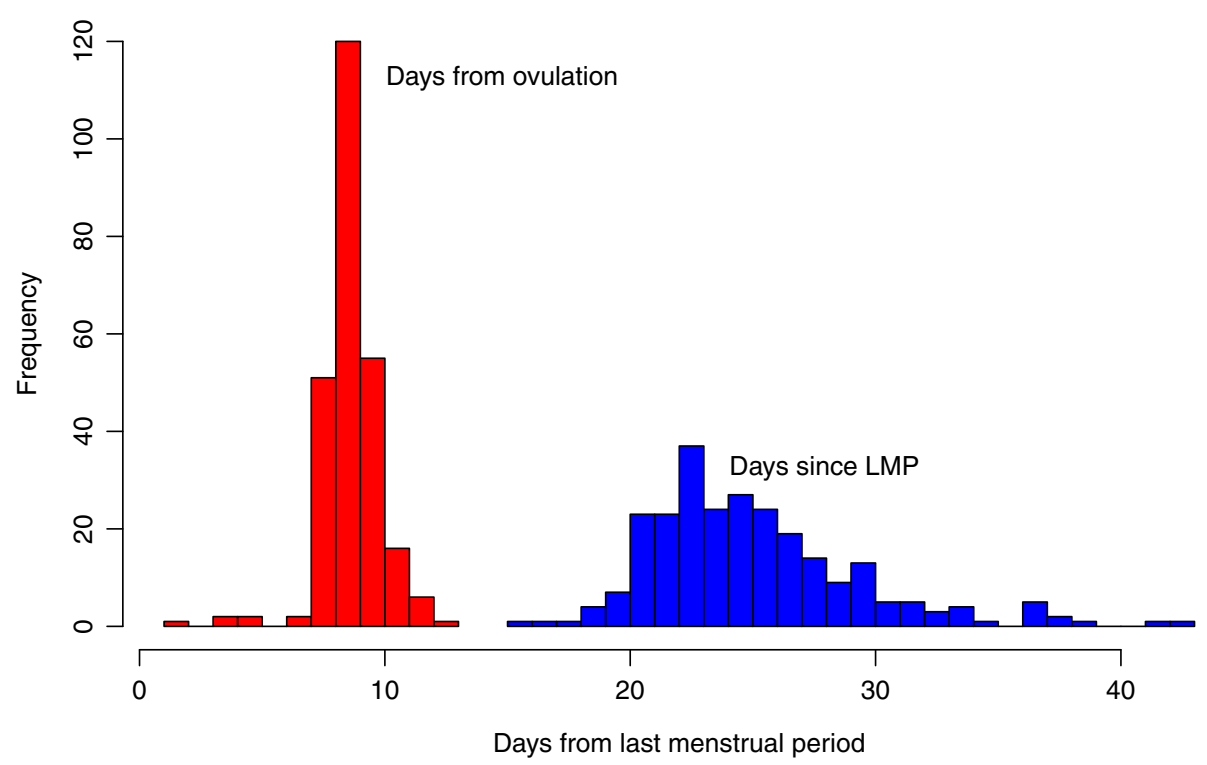

Fig. 1 Days from LMP and from Ovulation day to hCG > $1 \mathrm{mlU} / \mathrm{ml}$ (256 women)

between LMP and the hCG rise varies significantly more, with $88 \%$ within 20 days to 30 days (11 days as opposed to 3 days), and $9 \% 31$ to 60 days (Table 2). This demonstrates that the day of ovulation, calculated by the LH surge, is a much more precise indicator of the start of pregnancy than the first day of the last menstrual period.

\section{Onset of symptoms}

From ovulation, symptoms start approximately two weeks earlier, and are more concentrated than from LMP (Fig. 2). Two-thirds of women have onset within 11 to 20 days from ovulation day, and only $5 \%$ have earlier onset. The median from ovulation to symptom onset is 16 days and from LMP is 32 days. For onset from LMP, 67\% have onset within 26 to day 40 (Fig. 2), with highest frequency at 28 days after LMP. Again, precision is greater when measuring pregnancy from ovulation (Table 2). Symptoms start slightly earlier for women with higher BMI values (Fig. 3), by about one day for an increase of $5 \mathrm{~kg} / \mathrm{m}^{2}$ (regression coefficient -0.225 , standard error 0.075$)$. Predicted onset is day 20 for a woman with BMI $18 \mathrm{~kg} / \mathrm{m}^{2}$ and day 16 for a woman with BMI $35 \mathrm{~kg} / \mathrm{m}^{2}$. Symptoms start slightly later with increasing age (Fig. 3), by almost one day for an increase of 3 years (regression coefficient 0.295 , standard error 0.094). Predicted onset is day 14 for an 18 year old, and day 21 for a 41 year old woman.

Symptoms disappeared by week 7 from LMP for 20 (8\%) of the volunteers, 11 of whom never vomited and 16 of whom had symptoms less than 2 hours per day. Furthermore, out of the 25 women whose symptoms ended in week 8 of their pregnancies, 15 had symptoms less than 2 hours per day. These $32-35$ women (12-14\% of the study population) with early or mild symptoms might have not recorded them if they were first asked about their symptoms at a later stage of their pregnancy.

\section{Severity of symptoms}

Table (1) provides a high level summary of symptom

Table 2 Times to hCG rise (256 women) and to onset of symptoms (241 women)

\begin{tabular}{llllll}
\hline Time & \multicolumn{3}{c}{ Summary statistics in days } \\
\cline { 2 - 6 } & Minimum & $\begin{array}{l}\text { Lower } \\
\text { quartile }\end{array}$ & Median & $\begin{array}{l}\text { Upper } \\
\text { quartile }\end{array}$ \\
\hline LMP to hCG $>1 \mathrm{~m} / \mathrm{U} / \mathrm{ml}$ & 15 & 23 & 25 & 28 & Maximum \\
Ovulation to $\mathrm{hCG}>1 \mathrm{mlU} / \mathrm{ml}$ & 1 & 9 & 9 & 10 & 13 \\
LMP to symptom onset & 21 & 28 & 32 & 40 & 60 \\
Ovulation to symptom onset & 8 & 13 & 16 & 22 & 45 \\
\hline
\end{tabular}



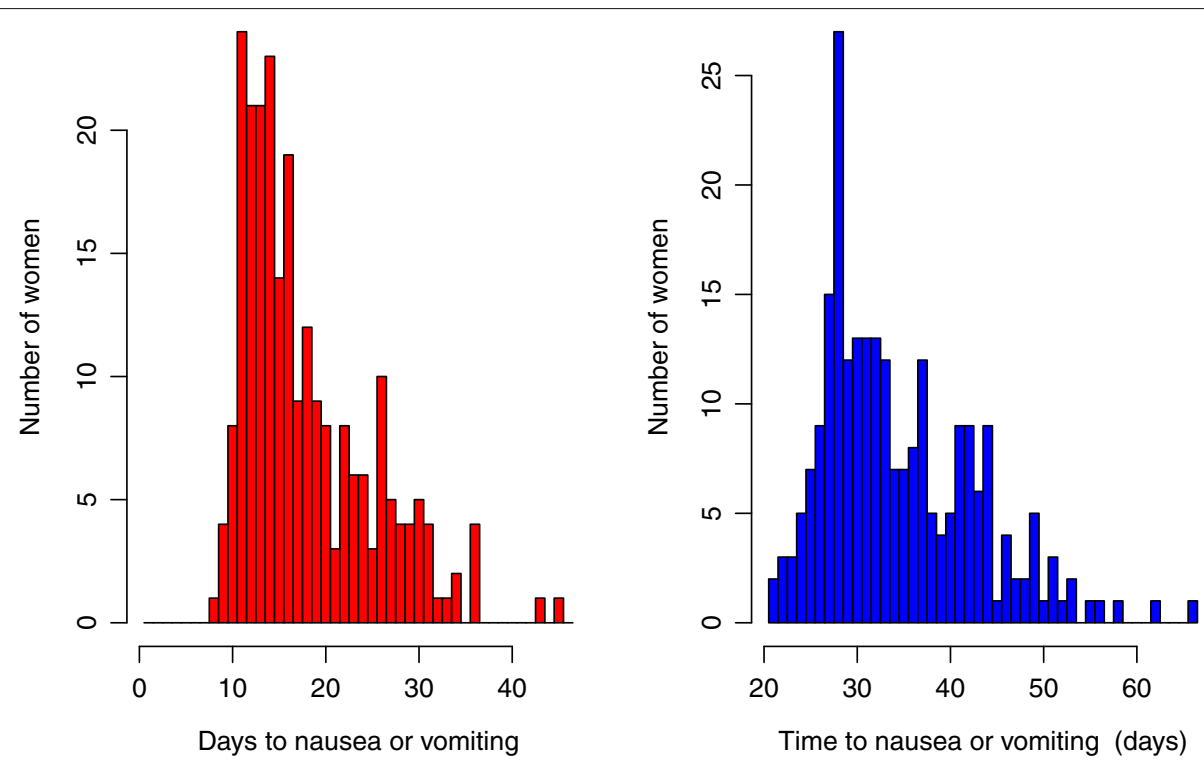

Fig. 2 Distribution of onset of symptoms from LMP and from Ovulation (214 women)

severity considered as average hours per day. A fifth (22\%) of women had minimal nausea and vomiting, with an average of less than an hour per day; 36\% averaged more than 4 hours per day. Smokers and those with at least two previous live births tended to have symptoms for longer each day. There is no simple association with miscarriages, and a slight suggestion of lower symptom rates for women with degree level education.

\section{Discussion}

Main findings

This paper describes for the first time the onset of symptoms of nausea and vomiting in pregnancy from the day of ovulation. The vast majority of women (94\%) experienced symptoms which started within a clear, narrow time window from ovulation. In particular, symptoms began between days 11 and 20 for $67 \%(n=160)$ of the 241 par-
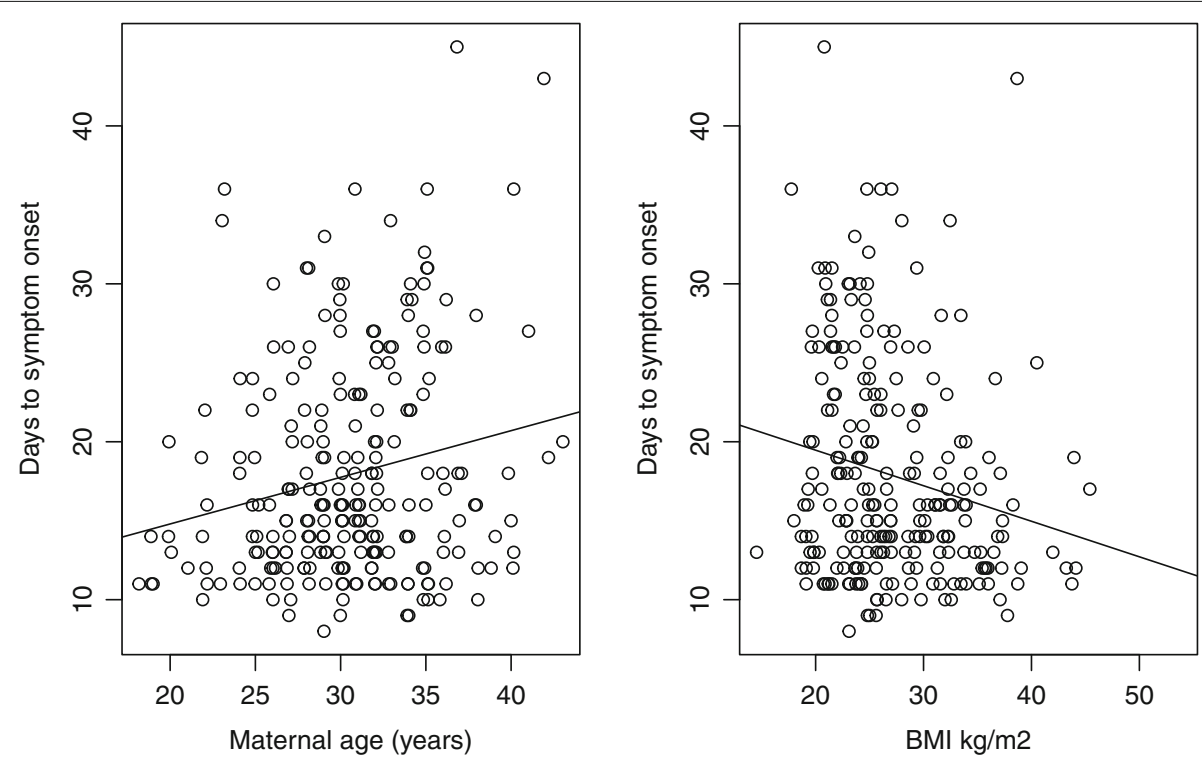

Fig. 3 Onset of symptoms from ovulation: association with age and body mass index (BMI), 214 women 
ticipants with NVP. When LMP is used to date the onset of pregnancy, as has been done in previously published studies, the equivalent range is days 26 to 40 . Onset was later with increasing age, and slightly earlier with increasing BMI. The close connection between onset of NVP symptoms and date of ovulation reinforces the theory that the aetiology of the condition is biological, rather than psychiatric, and is based on the emerging physiology at the foetal-maternal interface.

\section{Interpretation}

Onset of symptoms of nausea or vomiting was earlier than reported in other articles: median from LMP at day 32, compared to day 57, 8 weeks [5] or 5 weeks [4]. A possible reason for this discrepancy is that the volunteers in this study were all women who have been trying to get pregnant for a while and would be awaiting early mild NVP symptoms as one of the first signs they were pregnant. Moreover, in all of the studies mentioned above the initial interview or survey was at least 8-9 weeks after onset. In this setting some of the participants who had experienced brief symptoms in the beginning of their pregnancies might have forgotten about them when they had to report their experiences of symptoms retrospectively, [14].

The prevalence of NVP symptoms in this study, at $94 \%$, is higher than that reported in other studies, which have reported a prevalence of NVP symptoms in $50-80 \%$ of pregnant women $[4,5]$. In a literature review that included data from 26 published papers, of 39710 pregnancies, the percentage of pregnant women experiencing NVP symptoms was 73.4\% [15]. A meta-analysis of 59 studies of NVP (93,753 women) reported a median rate of $69 \%$, range $35 \%$ to $91 \%$; rates for East Asian countries were between $75 \%$ and $91 \%$ [16]. Prevalence estimates from clinical records of NVP are much lower 9.1\% [17]. Again, one reason may be that the women were actively trying to conceive and this might have made them more inclined to notice details related to their pregnancies such as mild symptoms. Another reason could be that most previous studies of NVP onset recorded at least some of their data retrospectively. Mild early symptoms of NVP may get overlooked and forgotten, especially if women are being asked to remember them a number of weeks later. Detailed results for factors affecting symptoms are a separate article.

This hypothesis was confirmed in this study in that $13 \%$ $(n=32)$ of women who had very early symptoms up to week 7 or mild symptoms, lost them by day 56 (week 8 ) from LMP, the date at which many previous studies began their prospective recording of NVP symptoms. The mean day of onset of NVP symptoms in this study is day 18 from ovulation, while from LMP it is day 34 . This date from LMP is slightly earlier than 39 days [5] or 40 days (5.7 weeks) [4] reported previously. In a review of onset of NVP symptoms from LMP, data from 7 papers with a pooled population of 2092 women, had mean day of onset from LMP as day 39 [15].

\section{Strengths and limitations}

The strengths of our study are that it is based on a sizable cohort of women who are broadly representative of women planning to become pregnant in the UK. The data on NVP symptoms was collected prospectively from the onset of pregnancy and we can pinpoint the day of ovulation through the measurement of the LH surge. As the mean onset of NVP for those who started their pregnancy diaries on the first day of symptoms was a week earlier than those who started diaries before first symptoms, it is likely that symptoms did not occur before the first recorded day. Some weaknesses of the study are that the dataset under-represents women from lower socio-economic (educational) backgrounds, and black and minority ethnic backgrounds. Unplanned pregancies were not included, but there is no evidence of difference in NVP for planned or unplanned pregnancies. East Asian countries report higher prevalence of NVP [16] but onset is not addressed. These results could be generalisable across education backgrounds for developed countries. Women in the study stopped recording NVP symptoms at around week 9 of pregnancy when several of them were still experiencing symptoms so that this dataset cannot be used to reliably describe NVP symptom cessation.

\section{Conclusion}

Onset of NVP occurs earlier than previously reported and there is a narrow window for onset of symptoms from ovulation. This indicates that its etiology is associated with a specific developmental stage. Further study of the association between levels of hCG in urine and NVP symptoms could help to indicate more effective treatment.

\section{Supplementary Information}

The online version contains supplementary material available at https://doi.org/10.1186/s12884-020-03478-7.

Additional file 1: Title: Weekly Diary of Pregnancy Sickness

Description: Diary given to volunteers to complete from day 30 after LMP, with confidential data management elements removed.

\section{Abbreviations}

BMI: Body mass index; hCG: Human chorionic gonadotrophin; LH: Luteinising hormone; LMP: Last menstrual period; NVP: Nausea and vomiting of pregnancy; SPD: SPD development company limited

\section{Acknowledgements}

The Department of Statistics at the University of Warwick acknowledge the opportunity for ET and DI to work with this SPD Development Company Limited data.

\section{Authors' contributions}

SJ was responsible for conception and design of this study, participant recruitment, acquisition and interpretation of the data. DI and ET were 
responsible for the data analysis and modelling. $R G$ was responsible for the conception of the analysis, interpretation of the results, and drafting the manuscript. JLH provided substantial contributions with respect to analysis and interpretation of the results, and revising the manuscript. RG, DI, ET, JLH and $\mathrm{SJ}$ all critically revised the manuscript and gave final approval for publication. All authors have read and approved the manuscript. (Repeated declaration requested by editor.)

\section{Funding}

The cohort study was carried out by SPD Development Company Limited. Tria registration number: clinical trials.gov NCT01577147. SJ and SPD Development Company Limited were responsible for conception and design of this study, participant recruitment, acquisition and interpretation of the data.

\section{Availability of data and materials}

The datasets analysed during the current study are available from the corresponding author on reasonable request.

\section{Ethics approval and consent to participate}

The study was approved by SPD Development Company Limited Independent Ethics Committee (Protocol-0400 revision 8) 9 April 2014. The committee is not affiliated, but is conducted and constituted in line with the Department of Health's Governance Arrangements for Research Ethics Committees. Written informed consent was obtained from all participants.

\section{Consent for publication}

Not applicable

\section{Competing interests}

None: RG, ET, DI, JLH. SJ is an employee of SPD Development Company Limited, a fully owned subsidiary of SPD Development Company GmbH, the manufacturer of Clearblue pregnancy and fertility diagnostics.

\section{Author details}

${ }^{1}$ Department of Statistics, University of Warwick, CV5 6AB Coventry, UK.

${ }^{2}$ Warwick Medical School, University of Warwick, CV5 6AB Coventry, UK. ${ }^{3}$ SPD

Development Company Limited, Stannard Way, MK44 3UP Bedford, UK.

Received: 16 June 2020 Accepted: 4 December 2020

Published online: 06 January 2021

\section{References}

1. Chadwick J, Mann W. The medical works of Hippocrates. Oxford: Blackwell Scientific Publications; 1950. Later ed. pub. under title: Hippocratic writings.

2. Tsakiridis I, Mamopoulos A, Athanasiadis A, Dagklis T. The Management of Nausea and Vomiting of Pregnancy: Synthesis of National Guidelines. Obstet Gynecol Surv. 2019;74(3):161-9.

3. Whitehead SA, Andrews PLR, Chamberlain GVP. Characterisation of nausea and vomiting in early pregnancy: a survey of 1000 women. $J$ Obstet Gynaecol. 1992;12(6):364-9.

4. Lacroix R, Eason E, Melzack R. Nausea and vomiting during pregnancy: a prospective study of its frequency, intensity, and patterns of change. Am J Obstet Gynecol. 2000;182(4):931-7.

5. Gadsby R, Barnie-Adshead A, Jagger C. A prospective study of nausea and vomiting during pregnancy. Br J Gen Pract. 1993;43(371):245-8.

6. Geirsson RT, Busby-Earle RMC. Certain dates may not provide a reliable estimate of gestational age. BJOG: Int J Obstet Gynecol. 1991;98(1):108-9.

7. Waller DK, Spears WD, Gu Y, Cunningham GC. Assessing number-specific error in the recall of onset of last menstrual period. Paediatr Perinat Epidemiol. 2000;14(3):263-7.

8. Gnoth C, Johnson SR. Strips of hope: accuracy of home pregnancy tests and new developments. Geburtshilfe Frauenheilkd. 2014:74:661-9.

9. Dean C, Bannignan K, Marsden J. Reviewing the effect of hyperemesis gravidarum on women's lives and mental health. Br J Midwifery. 2018;26: 109-19.

10. Fejzo M, MacGibbon K. Hyperemesis gravidarum: it is time to put an end to the misguided theory of a psychiatric etiology. Gen Hosp Psychiatry. 2012;34:699-700.

11. Dean C, Shemar M, Ostrowski G, Painter R. Management of severe pregnancy sickness and hyperemesis gravidarum. BMJ. 2018;363:k5000

12. Gadsby R, Trevelyan E, Ivanova D, Hutton J, Johnson S. Nausea and vomiting in pregnancy is not just 'morning sickness': data from a prospective cohort study in the UK. Br J Gen Pract. 2020;70(697):e534-9.
13. Office for National Statistics, Haines N. Births by parents' characteristics in England and Wales: 2016. 2017. https://www.ons.gov.uk/ peoplepopulationandcommunity/birthsdeathsandmarriages/livebirths/ bulletins/birthsbyparentscharacteristicsinenglandandwales/2016. Accessed 09 Dec 2020.

14. Koren G, Maltepe C, Navioz Y, Wolpin J. Recall bias of the symptoms of nausea and vomiting of pregnancy. Am J Obstet Gynecol. 2004;190(2): 485-8.

15. Gadsby R, Barnie-Adshead A. Nausea and Vomiting of Pregnancy: a Review of the literature. 2010. www.pregnancysicknesssupport.org.uk/ documents/NVP-lit-review.pdf.

16. Einarson T, Piwko C, Koren G. Quantifying the global rates of nausea and vomiting of pregnancy: a meta-analysis. J Popul Ther Clin Pharmacol. 2013;20(2):171-83.

17. Fiaschi L, Nelson-Piercy C, Deb S, King R, Tata L. Clinical management of nausea and vomiting in pregnancy and hyperemesis gravidarum across primary and secondary care: a population-based study. Brit J Obstet Gynaecal. 2019;126(10):1201-11. https://doi.org/10.1111/1471-0528. 15662.

\section{Publisher's Note}

Springer Nature remains neutral with regard to jurisdictional claims in published maps and institutional affiliations.

\section{Ready to submit your research? Choose BMC and benefit from}

- fast, convenient online submission

- thorough peer review by experienced researchers in your field

- rapid publication on acceptance

- support for research data, including large and complex data types

- gold Open Access which fosters wider collaboration and increased citations

- maximum visibility for your research: over $100 \mathrm{M}$ website views per year

At BMC, research is always in progress.

Learn more biomedcentral.com/submissions 